\title{
Tratamiento esteroidal en la enfermedad celíaca del niño
}

DRES.: OSVALDO DANUS *; FRANCISCO LARRALN * $y$ DAVID MIRKIN **.

Aunque la etiología de la enfermedad celíaca no está plenamente determinada, el efecto nocivo del gluten es un hecho indiscutible. Es habitual que el paciente experimente una mejoría dramática al someterlo a dieta libre de gluten. En efecto, la experiencia acumulada en nuestro Departamento demuestra que aproximadamente el $80 \%$ de los pacientes experimenta regresión de los síntomas en los primeros 30 días de tratamíento con progreso ponderal significativo que alcanza hasta $3 \mathrm{~kg}$. en ese lapso (1).

Algunos enfermos no responden en forma adecuada a la supresión del gluten. En ellos se ha aducido la existencia de otros factores como son la intolerancia secundaria a la lactosa $y / o$ infecciones enterales parasitarias o bacterianas intercurrentes. Sin embargo, la eliminación de estos factores no siempre implica una evolución satisfactoria.

En 1967 Pink y Creamer (2) presentaron la evolución experimentada por un grupo de sus pacientes celíacos adultos señalando que en el $30 \%$ ésta fue tórpida falleciendo 5 de 54 enfermos. En ellos destacaba la ausencia de células de Paneth en la mucosa intestinal, atribuyéndosele a dichas células algún papel en la diferenciación y maduración del epitelio intestinal; sin embargo, este hecho no ha vuelto a ser mencionado en la literatura.

Desde algunos años se conoce el papel benéfico de los esteroides en algunas modalidades clínicas de la enfermedad celíaca, especialmente en el tratamiento de la "Crisis Celíaca", circunstancia que ha dado, en parte, fundamentos a la naturaleza inmunológica del proceso. En la misma serie mencionada de Pink y Creamer, algunos

\footnotetext{
* Gastruenterologia. Departamento de Pediatria. Area Norte, Hospital Roberto del Río.

* Servicio de Anatomía Patológica. Hospital Roberto del Rjo.
}

pacientes con evolución tórpida habrían sido recuperados con el tratamiento esteroidal asociado.

En 1970, Wall y cols. (3) presentaron los resultados obtenidos en 5 pacientes celíacos adultos sometidos a tratamiento esteroidal durante 4 a 5 semanas. Después de ese lapso apreciaron mejoría en la absorción de xilosa y en algunos parámetros de la histología intestinal. Estos signos de recuperación regresaron al suspender la droga.

La necesidad de disponer de algún otro elemento terapéutico que favorezca la recuperación de aquellos pacientes celíacos con evolución tórpida, por una parte y, el desconocimiento del efecto del esteroide en la enteropatía por gluten del niño, nos ha inducido a medir su acción en base a la evolución clínica, absorción intestinal y cambios histológicos de la mucosa intestinal después de un tratamiento corto con prednisona.

Material y Metodo. Se estudian 11 pacientes (6 mujeres y 5 hombres) con edades entre 1 año 4 meses y 12 años, portadores de enfermedad celíaca sin tratamiento previo y cuyas principales carcterísticas clínicas se presentan en la Tabla № 1. El diagnóstico de enfermedad celíaca se fundamentó en la existencia de cuadro clínico compatibie, presencia de malabsorción intestinal medida por el test de caroteno plasmático, histología duodeno-yeyunal correspondiente a "Atrofia vellositaria subtotal" (Enteropatía grado III según la clasificación adoptada en el Departamenta) y pruebas y contrapruebas al gluten positivas evidenciadas por la técnica del test de earoteno (4).

Al momento del ingreso la enfermedad tenía un período de evolución que oscilaba entre 2 mess y 11 años.

El motivo de consulta fue: Diarrea crónica en 4; distensión aủdominal en 3; vómito crónico 

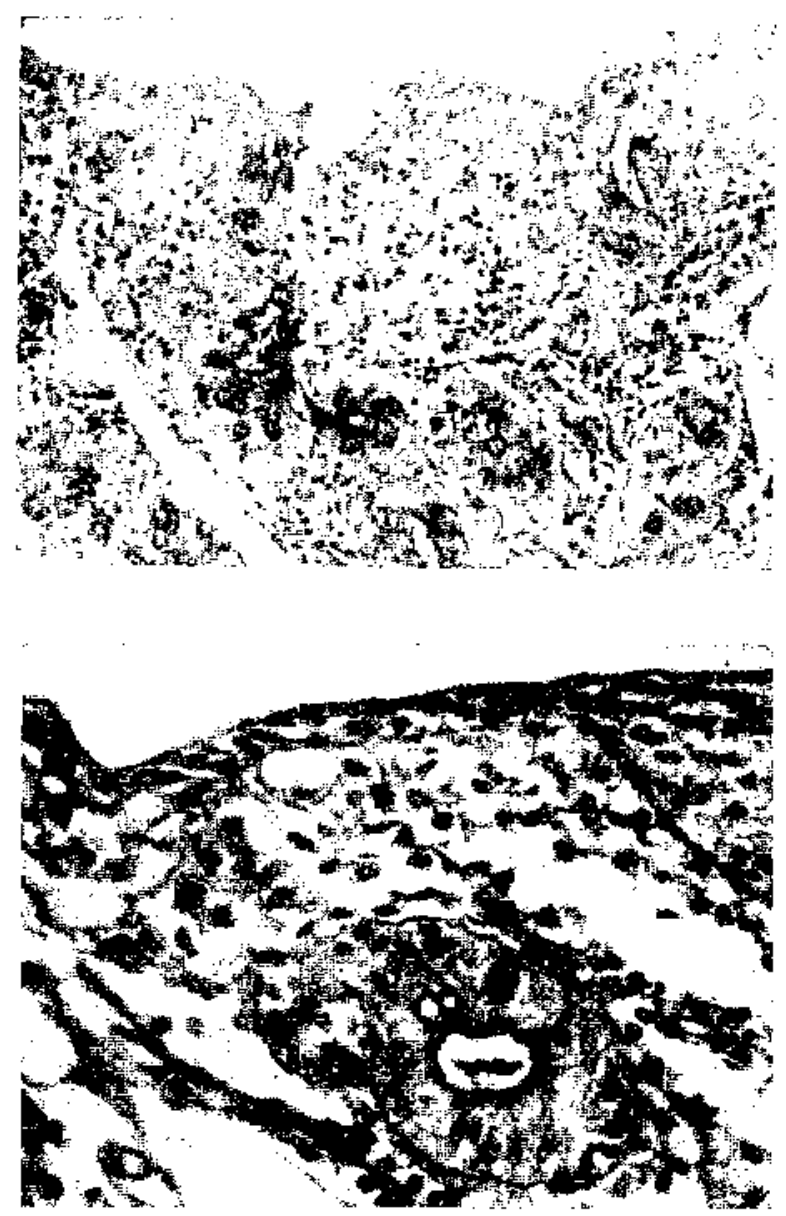

Figuras 1 y 2 , - Alogromo $16 \mathrm{x}$ y $40 \mathrm{x}$.

Trozos de mucasa intestinal tomados previo al tratamiento. No se reconocen vellosidades, existe infiltración del corion $y$ el epitelio es bajo con chapa estriada Sorrosa.

en 2; desnutriciôn en 1 y talla baja en 1. Estos síntomas principales coexistían con otros síntomas o signos comunes de la enfermedad, como ser astenia, irritabilidad, palidez, signos carcnciales, descenso ponderal, etc.

Con excepción de 1 paciente de 16 meses de vida y 2 meses de enfermedad en quien el estado nutritivo estaba sólo discretamente comprometido, el resto presentaba acentuado compromiso pondo-estatural.

Al ingreso se practicó estudio hematológico, estudio parasitológico seriado de deposiciones, test dc caroteno plasmático y estudio bistológico de mucosa intestinal por biopsia per oral. Estos dos últimos exámenes se realizaron de acuerdo a las técnicas mencionadas en publicaciones anteriores (4-5).

En 9 pacientes se apreció anemia generalmente importante, hipocroma $\mathrm{y} / \mathrm{o}$ megaloblástica.

En 4 niños existió una parasitosis intestinal, Lambliasis, que fue tratada con metronidazol oral de acuerdo al esquema habitual.

Para los efectos de la investigación los pacien- tes se mantuvieron hospitalizados sometiéndoseles a régimen alimentario completo que inclúa ghuten diario. Se suministró prednisona oral en dosis de $2 \mathrm{mg} / \mathrm{kr} /$ día durante 10 días y reducción progrcsiva, para suspenderla al $16^{\circ}$ dia, oportunidad en la que se repitió el test de caroteno y la biopsia de mucosa intestinal.

Como control se utilizó un grupo de $\mathbf{1 0}$ niños con enfermedad celíaca sin tratamiento previo, con similar distribución etaria, en los que se practicó dos estudios histológicos de mucosa intesti-
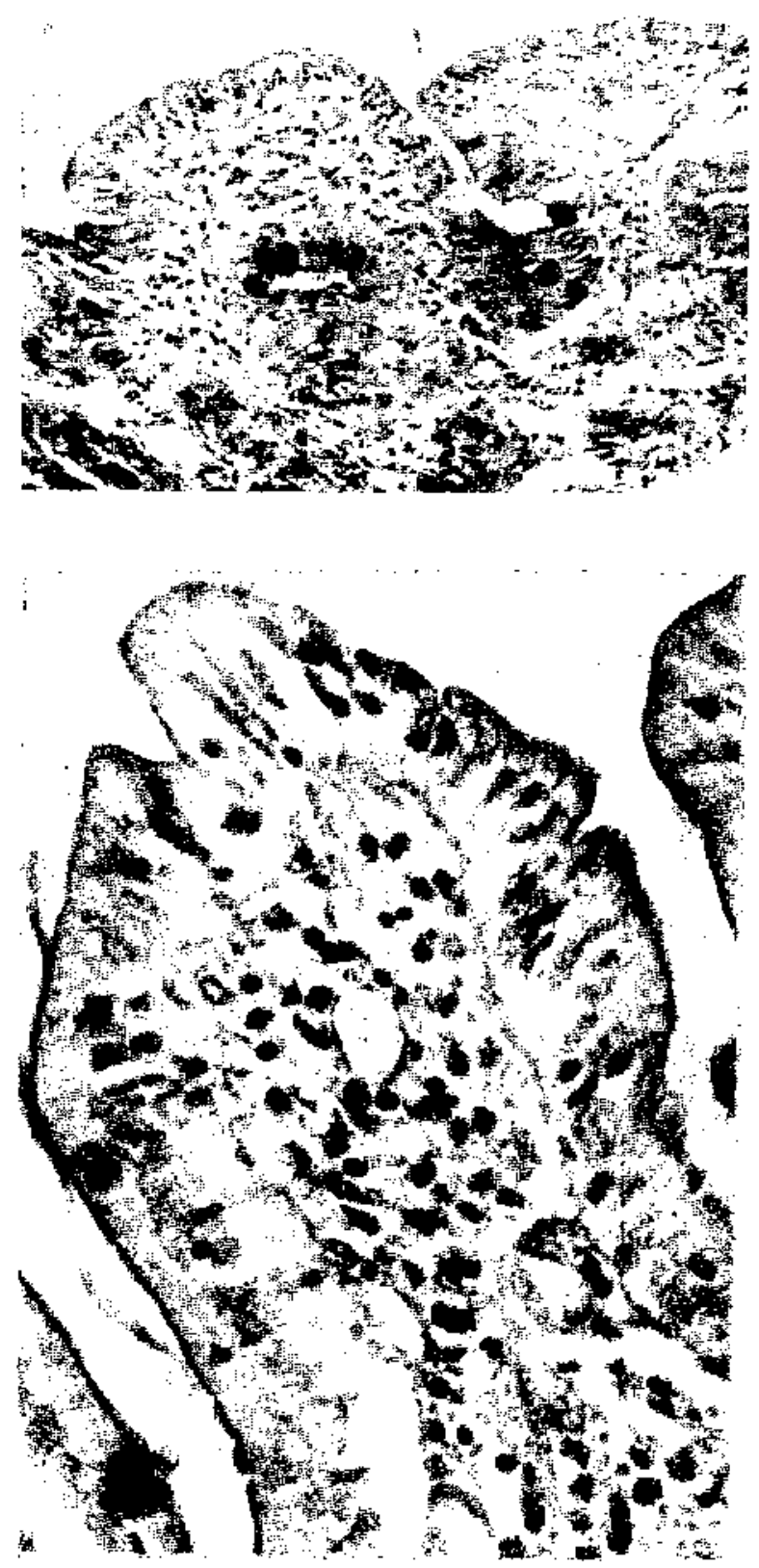

Figuras 3 y 4.- Alogromo $16 x$ y $40 x$.

Después de 15 dfas dé tratamiento. Aparecen esbozos de velosidades y el epitelio es cilindrico con chapa estriada nitida. 
T A B L A No 1

CARACTERISTICAS CLINICAS EN 11 PACIENTES PORTADORES DE ENFERMEDAD CELIACA

\begin{tabular}{|c|c|c|c|c|c|c|c|}
\hline \multirow{2}{*}{$\frac{\text { Caso }}{1}$} & Edad & \multicolumn{2}{|c|}{ Tiempo evolución } & \multirow{2}{*}{$\frac{\text { Estado }}{\mathrm{D}}$} & \multirow{2}{*}{$\frac{\text { nutritivo }}{1}$} & \multirow{2}{*}{$\frac{\text { Parasitosis }}{\text { NO }}$} & \multirow{2}{*}{$\frac{H B g r s \%}{7}$} \\
\hline & 2a. $4 \mathrm{~m}$. & & $10 \mathrm{~m}$. & & & & \\
\hline 2 & $12 \mathrm{a}$. & $11 \mathrm{a}$ & & Bajo & P3 & No & 9,5 \\
\hline 3 & 1 a. $4 \mathrm{~m}$. & & $2 \mathrm{~m}$. & D & 1 & No & 11 \\
\hline 4 & 9 a. & 3 a. & & Bajo & $\mathrm{P3}$ & Lambliasis & 9,5 \\
\hline 5 & $4 a$. & $2 \mathrm{a}$. & $6 \mathrm{~m}$. & D & 2 & Lambliasis & 11 \\
\hline 6 & $8 \mathrm{a}$. & $7 \mathrm{a}$, & & Bajo & P3 & No & 8,3 \\
\hline 7 & 7 a. & 2 a. & $6 \mathrm{~m}$. & Bajo & P3 & Lambliasis & 8 \\
\hline 8 & 1 a. $9 \mathrm{~m}$. & 1 a. & $1 \mathrm{~m}$. & D & 2 & NO & 12 \\
\hline 9 & 3 a. $5 \mathrm{~m}$. & & $3 \mathrm{~m}$. & $\mathbf{D}$ & 1 & Lambliasis & 4,6 \\
\hline 10 & 2a. $6 \mathrm{~m}$. & & $6 \mathrm{~m}$. & D & 2 & NO & 9,5 \\
\hline 11 & 9 a. & 7 a. & & Bajo & P3 & No & 7,6 \\
\hline
\end{tabular}

T A B L A No 2

ENFERMEDAD CELIACA. ABSORCION DE CAROTENO E HISTOLOGIA INTESTINAL EN 11 PACIENTES TRATADOS CON PREDNISONA

\begin{tabular}{|c|c|c|c|c|c|c|c|c|}
\hline \multirow{3}{*}{ Caso } & & & \multicolumn{6}{|c|}{ Histologia Intestinal (Grados 03) } \\
\hline & \multicolumn{2}{|c|}{ Caroteno } & \multicolumn{2}{|c|}{ Vellosidad } & \multicolumn{2}{|c|}{ Epitelio } & \multicolumn{2}{|c|}{ Infiltrado } \\
\hline & Antes & Después & Antes & Después & Antes & Después & Antes & Después \\
\hline 1 & 15 & (98) & 3 & (2) & 3 & (2) & 2 & 2 \\
\hline 2 & 57 & (73) & 3 & 3 & 3 & 3 & 2 & 2 \\
\hline 3 & 10 & 25 & 3 & (2) & 3 & (2) & 2 & 2 \\
\hline 4 & 11 & 16 & 3 & (2) & 3 & (2) & 2 & (1) \\
\hline$s$ & 6 & (98) & 3 & 3 & 3 & 3 & 3 & 3 \\
\hline 6 & 52 & (64) & 3 & (2) & 3 & (2) & 3 & 3 \\
\hline 7 & 22 & (134) & 3 & (2) & 3 & (2) & 3 & 3 \\
\hline 8 & 16 & 24 & 3 & 3 & 3 & (2) & 1 & 1 \\
\hline 9 & 32 & (76) & 3 & (2) & 3 & (2) & 3 & (2) \\
\hline 10 & 28 & (80) & 3 & (2) & 3 & (2) & 1 & 1 \\
\hline 11 & 50 & (64) & 3 & 3 & 3 & (2) & 3 & (1) \\
\hline Recu & & $8 / 11$ & & $7 / 11$ & & $9 / 11$ & & $3 / 11$ \\
\hline
\end{tabular}

nal en lapsos de 15 a 60 dias sin que mediaran factores terapéuticos.

Se analizó la evolución clínica experimentada durante ese lapso, las variaciones de la carotinemia y las modificaciones histológicas para cuya tabulación se consideraron los siguientes parámetros: Cantidad de vellosidades, altura de las vellosidades, ancho, aspecto de las criptas (dilatación, ectasis mucoso), infiltrado leucocitario (tipo e intensidad) y aspecto del epitelio externo (altura, núcleo, chapa estriada). Estos parámetros se clasificaron en 4 grados $(0-3)$ de acuerdo a la magnitud del compromiso.

Resultados. En ninguno de los pacientes se presentó proceso intercurrente durante la terapia esteroidal. En todos ellos se apreció mejoría del estado general caracterizado por recuperación del apetito, de la actividad física y mejoría del carácter.

En 8 de los 11 pacientes se obtuvo alzas de la carotinemia hasta cifras normales. En los 3 restantes también se apreció recuperación de los valores, pero sin alcanzar los rangos de normalidad.

Las variaciones histológicas estuvieron dadas fundamentalmente por los cambios a nivel del epitelio. En efecto, en 9 de los 11 pacientes se evidenció una clara recuperación del epitelio el que en la superficie de la vellosidad se transformó de plano en cilíndrico con adecuada distribución basal del núcleo y chapa estriada nítida. En 7 casos se apreció mejoría en relación a la estruc- 
tura vellositaria ya que en ellos fue posible observar la aparición de esbozos de vellosidades. En 3 casos existió una disminución en la intensidad de infiltrado leucocitario del corión $y$ en 4 niños ei tipo de infiltrado cambió de leucocitario a plasmocitario (Tabla No 2).

En e! grupo control la comparación de las biopsias intestinales no mostró crimbios significativos en los parámetros señalados.

Comentakio. Por los resultados expuestos puede conciuirse que la prednisona fue de utilidad en los pacientes estudiados. En efecto, aunque no es posible objetivarlo, la impresión clínica fuc de que existió franca mejoría del estado general $\mathrm{y}$ del apetito en todos los pacientes. $\mathrm{El}$ alza ponderal observada en 7 de los pacientes, y que en 1 caso alcanzó a 1.800 grs, es muy probab'e que sea efecto de la retención hídrica determinada por el esteroide. Asimismo, nos parece que la normalización de las deposiciones, observada en 4 de los niños, tampoco puede atribuirse a la terapia empieada, ya que es usual observar variaciones espontáneas en el aspecto de las deposiciones en el curso de la enfermdad.

En cambio nos parece que son importantes ias variaciones obtenidas en las cifras de carotínemia y los cambios observados en la histología intestinal. La absorción de caroteno en nuestra experiencia (6) se ha presentado como un test de a!ta sensibilidad, con buena correlación con Ja histología incestina! y que presenta variaciones precoces en relación a los factores que modifican la absorción intestinal por lo cual se le preconiza como un elemento útil para evidenciar precozmente la respuesta a la prueba y contraprueba terapéuticas (4). En esta experiencia pensamos que el alto porcentaje de normalización obtenido en el plazo de 15 días refleja el efecto beneficioso del esteroide en la absorción intestinal.

Desde un punto de vista térico podría argumentarse que los cambios de la mucosa intestinal correspondieran a variaciones espontáneas, parcelares de la mucosa, ya que esta circunstancia ha sido obscrvada por algunos autores (7). Sin embargo, esto nos parece muy poco probable por los siguientes motivos: en primer lugar, los cambios observados en esta serie corresponden a los tradicionalmente apreciados en la recuperación de la enfermedad. En efecto, los primeros signos de mejoría histológica sc refieren a las modificaciones del epitelio el que adquiere aspecto cilíndrico con ordenación de los núcleos en la base de la célulla y aparición de chapa estriada nítida, aspecto que se observó en 9 de los 11 niños. Desde el punto de vista del azar es muy poco probable que apareciera precisamente este aspecto en tan alta proporcion. Por otra parte, controles histológicos practicados en otro grupo de 10 niños portadores de enfermedad celíaca sin tratamiento no mostró cambios apreciables en muestras de mucosa intestinal sucesivas. Por los motivos señalados suponemos que las evidencias de mejoría histológica deben atribuirse al efecto del esterojde.

Es importante precisar mejor el papel de Ios esteroides en cl tratamiento de la enfermedad celíaca ya que es nccesario disponer de otros elementos terapéuticos que favorezcan la recuperación de aquellos pacientes graves o que presenten evolución tórpida.

\section{RESUMEN}

Se presenta el efecto terapéutico de la prednisona oral (2 mg/kg/dia durante 15 dias) en la absorción intestinal $e$ histología duodeno-yeyunal de 11 pacientes portadores de enfermedad celiaca sin tratamiento previo.

Durante el periodo de observación no se apreciaron inconvenientes derivados del uso de la prednisona. En todos los niños se observó mejoría del estado general y apetito.

En 8 de los 11 pacientes la carotinemia se elevó a rangos normales.

En 9 de los 11 niños se apreciaron cambios histológicos de la mucosa intestinal que evidenciaban recuperación y que consistieron en aparición de epitelio cilindrico en 9, esbozo de vellosidades en 7 y en 3 disminución del infiltrado celular del corión.

Se sugicre que la prednisona seria un elemento de utilidad terapéutica en pacientes celíacos graves o con evolución tórpida.

\section{SUMMARY}

The therapeutic effect of the oral prednisona was studied in 11 children with celiac disease without previous treatment.

During a 15 period day in wich they were receiving $2 \mathrm{mg} / \mathrm{kgc} /$ day of prednisona and complete diet, no problems were noticed and general activity as appetite were considerably improved.

Eigth of the 11 patients increased carotinemia levels until normal range and in 9 of the 11 children the intestinal mucosa showed clear improvement characterized by presence of cylindric epithelial cells in 9 , short villous in 7 and decrease inflammatory activity in 3 .

It is suggested that prednisona should appears to be an useful treatment adjunt in the recovery of the children's celiac disease.

\section{REFERENCIAS}

1.-Dants, O.; Chuaqui, B.; Solimano, G.; Urbina, A. M. Enteropatía sensible al gluten. Características en el niño chileno. Pediatría 13: 45, 1970. 
2.-Pink, I. J.: Creamer, B. Response to a gluten-free diet of patients with the coeliac syndrome. The Lancet I: $300,1967$.

3.- Wall, A. J.; Douglas, A. P.; Booth, C. C.; Pearse, $A . G, E$. Response of the yeyunal mucosa in adnlt celiac disease to oral prednisona. Gut. 11: 7, 1970.

4.- Larrain, F.; Figueroa, $C$.; Danús, $O$. contraprueba terapéutica en el diagnóstico de la enfermedad celíaca. Metódica e indicaciones. En este mismo número de la Rev. Chilena de Pediat.
5.-Danús, O.j Chuaqui, B.: Mafamala, M. I. Estudio de mucosa yeyunal en el sinđrome de malabsorción intestinal del lactante menor con desnutrición severa. Pediatría 10: 9, 1967.

6.-Danís, O.; Hormazábal, J. Test de caroteno plasmático en el diagnóstico de la enfermedad celiaca. Correlación con la histología duodeno-yeyunal. Rev. Cinilena de Pediat. (En prensa).

7.-Woinstein, W. M. Latent Celiac Sprue. Gastroenterology 66 : $489,1974$. 